\title{
NEW ZEALAND'S PROGRESS ON WORK-LIFE BALANCE: A WORK IN PROGRESS
}

\author{
Penny Nelson \\ Trudie McNaughton \\ Department of Labour \\ Work Life Balance Steering Group
}

\begin{abstract}
The Government established the Work-Life Balance Project in August 2003 recognising that work life balance has economic and social benefits. Given that some people face significant challenges attaining the appropriate balance for them and their workplaces, the Government sought information from individual and business perspectives on work-life balance in a context of labour and skills shortages, a desire to improve productivity and labour force participation. This paper explores some of the key themes emerging from the consultation process and other research.
\end{abstract}

\section{Introduction}

The Government established the Work-Life Balance Project in August 2003 in recognition that achieving a balance between paid work and the other aspects of people's lives (including caring and community responsibilities, study and leisure) had become a challenge for some people. During the last year the Department of Labour, with input from an inter-agency Steering Group, has led a public engagement process and heard from a wide range of individuals and organisations about their perspectives.

Given that the causes and effects of "imbalance" are often complex and reach beyond individuals, households and workplaces, the project emphasised inter-agency involvement to identify linkages with other activities across government.

New Zealanders had a range of perspectives about what work-life balance means to them, the barriers to achieving it and what would help improve their work-life balance. More than 700 individuals and organisations contributed their views to the project. These views are summarised in Achieving Balanced Lives and Employment: What New Zealanders are saying about Work-Life Balance (Department of Labour, 2004).

Work-life balance matters not only to individuals, but also to business and governments. In a New Zealand context, work-life balance goals have a relationship with addressing labour and skills shortages, raising productivity, improving labour force participation and enhancing social wellbeing.

The interaction between economic pressures and the changing nature of New Zealand's population present new challenges. Addressing rising skills shortages will require innovative ways of attracting and retaining people to make the best use of a diverse workforce and to enable those who are employed to participate to their full potential. The current environment also requires that a work life balance framework includes career and life transitions and enhancing opportunities for lifelong learning. Viewing labour force utilisation with a worklife balance lens provides important insights into some of the barriers to improved participation in work at all levels and across occupations and sectors.

New Zealand has not been alone in thinking about the broader context; other governments have also increasingly taken an interest. Many governments are involved in providing work-life balance policies, which most often relate to childcare, leave policies, entitlements to workplace flexibility and providing assistance to employers to implement their own initiatives. In the United Kingdom, for example, the Government launched a major work-life balance campaign to assist employers to develop implement initiatives to improve work-life balance and productivity.

This paper explores some common themes in the worklife balance aspirations of New Zealanders that emerged from the consultation and additional research.

\section{What New Zealanders think about Work-life Balance}

Earlier this year, the Growth and Innovation Advisory Board released a much-quoted study that offers some valuable insights into the values and attitudes of New Zealanders to growth and innovation (Growth and Innovation Advisory Board, 2004). It suggests that New Zealanders rank quality of life more highly than personal wealth, employment prospects and levels of wages and salaries (although these areas were highly valued). The research also challenges old stereotypes that New Zealanders have a "she'll be right" attitude and suggests that instead, New Zealanders are highly motivated, ambitious and strive for self improvement. The report also noted a high degree of consensus about valuing innovation which bodes well for the potential for 
innovative work life balance strategies within families, workplaces and from government policy.

The study also found that $59 \%$ of respondents had undertaken study while in full-time or part-time work. Thirty five percent said that they had moved to another area for work prospects and $34 \%$ had taken a pay drop for a job with better long term prospects. This reinforces the view that New Zealanders are committed and ambitious about paid work. As David Skilling of the New Zealand Institute has noted that New Zealanders support growth in a conditional sense, that is, they will support pursuit of growth if policies are "fundamentally fair." He stresses the need for a social consensus about growth and says that an improvement in growth will only occur if we take into account New Zealand culture and values. (Skilling, 2004).

The Social Report 2004 measured a range of indicators of social wellbeing and, for the first time, measured the overall life satisfaction of New Zealanders. It found that most New Zealanders reported feeling very satisfied with their lives. The results are high compared with other countries and the report noted that out of 25 OECD countries "New Zealand has the fifth highest percentage of the population who are satisfied with their lives" (Ministry of Social Development, 2004).

The report also shows that most employed New Zealanders $(62 \%)$ are "satisfied" or "very satisfied" with their work-life balance and that people in part-time employment are more likely to be "satisfied" or "very satisfied" with their work-life balance $(75 \%)$ compared to people in full time employment ( $56 \%$ ) (Ministry of Social Development, 2004).

The Work-Life Balance Project is set against a context where most New Zealanders are generally satisfied with their work-life balance, and perceive quality of life as important to them. There are, of course, areas of potential improvement; the Social Report noted that in a 2001 study $61 \%$ of female secondary students aged $12-18$ years and $63 \%$ of male secondary students reported that most weeks they were able to spend enough time with parent/s or caregiver/s.

Where employers and employees are experiencing worklife balance barriers, submissions to the Work-life Balance Project and wider research reveals some common trends and themes. While most people considered that work-life balance was primarily an individual responsibility, many thought that individuals, families, communities, employers and government could all play a part in achieving better work-life balance.

Some consistent themes emerged, such as caring responsibilities (including the care of children and elders), income adequacy and workplace cultures and practices. A wide range of other issues such as access to transport, work organisation and non-standard or precarious work arrangements were also referred to by submitters.

\section{The Changing Nature of Work and Families}

Demographic changes including the ageing and more ethnically diverse population, the changing nature of New Zealand families and patterns of work in different household types presents new challenges when thinking about the dimensions of work-life balance. The decrease in single breadwinner/dual parent families, the rising participation of women in the work-force, presence of sole parent single earner households and extended family relationships means that finding the "right fit" between work and family presents new challenges for employees and employers.

Attitudes to paid work and its relationship to the rest of life are also changing. It is not just in New Zealand that quality of life is valued. A study commissioned by the American Business Collaboration (ABC) and the Families and Work Institute, Generation and Gender in the Workplace found a marked shift in how younger workers and "boomers" define their priorities in work and family. It reported that younger workers ("generation X" and "generation Y") are more likely to be "familycentric" (placing their highest priority on family) or "dual-centric" (with equal priorities on both career and family) and less "work-centric" (putting higher priority on their jobs than family) compared with members of the baby boomer generation (ABC and FWI, 2004). The report noted that dual-centric workers had advanced further in their careers than others, and dual-centric and family-centric workers had significantly better mental health, life satisfaction and work satisfaction than workcentric employees.

Tertiary educated younger workers, both men and women, are significantly less likely to want to move into jobs with more responsibility than they were a decade ago. This is particularly if they are working more hours than they wish to and if they experience "negative spillover" from job to home. The implications for workplaces and governments is clear. It is not just increasing labour market participation that will deliver the economic goals sought. It is the way that work is organised and its interaction with life outside work that impacts on the desire for increased responsibility and engagement.

\section{Hours of Work and Work-place Cultures and Practices}

Hours of work and work intensity was frequently cited by submitters to the New Zealand Work-Life Balance project. One submitter said:

"My hours may not be long (though sometimes they are) but they are always extremely packed. When your work's that intense it's impossible to forget about it even at night. It's like you never get to relax". (Department of Labour, 2004).

Hours of work were the focus of research by the New Zealand Council of Trade Unions (NZCTU, 2002). The NZCTU's "Thirty Families" report studied the impact of long working hours on a group of employees and their families. It found that "almost all of those who regularly 
worked more than 45 hours per week considered their hours too long and had a negative effect on their lives and their families“.

The International Labour Organisation recently found that "twenty percent or more of the workforce in the United States, Australia, New Zealand and Japan work at least 50 hours per week compared with 10 percent in most European countries" (International Labour Organisation, 2004) It suggests that there is a substantial gap between the number of hours employees worked compared to their preferred hours.

A recent study of hours of work in New Zealand has found that while hours of work on average has not changed much for individuals, the amount of hours worked has become more polarised with a growth in both short and long hours (Callister, 2004). Long hours tended to be more prevalent among couples (including those raising children) although women tended to work shorter hours than men.

The interrelationship between hours of work and career progression emerged in the State Service Commission's Career Progression and Development Survey 2000. When public servants were asked what had stopped them from applying for a more senior job, $25 \%$ of respondents mentioned concerns about work-life balance and 19\% said they did not want to work the long hours associated with senior positions (State Services Commission, 2002).

Wider issues relating to workplace practices and cultures also emerged in the consultation process with people noting that they had less "me time" and had less time to participate in sport and other community or voluntary activities. Participants in the NZCTU's Thirty Families research, referred to earlier, also noted the impact of long hours on their health and personal relationships.

\section{Caring Responsibilities}

Caring responsibilities were frequently identified by parents who made submissions to the Work-Life Balance Project with childcare the most commonly cited issue. The main barriers identified by submitters included the cost, access to childcare at suitable times and travel difficulties. While caring for children was the major issue of concern, as the population ages, the number of people caring for older family members will also increase.

The pressures on families often come from a number of directions, some being work-life balance "causes" and others being the "effects". For example, the pressures of finding affordable and extended hours of childcare often intertwine with the pressure of long working hours. In a policy context, the levers for addressing these issues includes considering the wider environmental setting relating to the hours care is available, the affordability of quality care and alternative ways of accessing care.

An online survey conducted by the EEO Trust in 2003 showed that $80 \%$ of fathers wanted to spend more time with their children. Eighty two percent of the men who completed the survey were not fathers. When asked if they thought they could be the sort of father they wanted to be if they stayed in their current job, 55\% said "no". Fifty two percent of respondents said that paid work affected the quality of time they spent with their children. Flexible start and finish times was the most popular way fathers thought workplaces could help them.

Initiatives such as paid parental leave are readily accessed by families. Since the introduction of paid parental leave, approximately 17,000 families per year have accessed the scheme with most taking the full period of paid parental leave. An evaluation of the scheme commissioned by the Department of Labour in 2003 found that the both employers and employees viewed the scheme as positive. Benefits cited by employees included being able to afford to stay home longer with a new baby and peace of mind brought about by a period of leave which is paid. Benefits cited by employers included happier and more satisfied staff and a greater likelihood of being able to retain experienced staff. (Gravitas, 2003).

More generally, recent initiatives such as the Government's plan for pay and employment equity in the public service, public health and public education sectors will play an important part in identifying and addressing the barriers men and women can experience in accessing provisions that assist them to participate in work as they would like to. This is also of relevance for employers as pressure on the labour pool in times of skill shortages make the need to access untapped parts of the labour market more critical.

\section{Businesses}

A number of self-employed people and small and medium size business owners raised their work-life balance challenges in submissions to the Project. For some, the margins were very tight and work-life balance issues were difficult to manage.

The challenges of implementing work-life balance practices in workplaces was also readily identified by employers, with information and support on "how to do it" being a critical area of need. Medium to large employers were more likely to have initiatives in place, while smaller employers found it more difficult and expensive. A majority of New Zealand businesses are small and medium size enterprises and have circumstances that are often unique to the particular industry concerned and a "one size fits all" approach to building capability is not practical or realistic.

Many employers recognise the business imperatives for work-life balance policies, including flexible work practices in an environment of competition to attract and retain quality staff. Attracting and retaining a diverse range of talent is becoming increasingly significant as businesses seek market share in a diverse population. For some organisations, the adoption of work-life balance policies and practices is also a demonstration of organisational values.

Research by UMR Insight commissioned by the Department of Labour shows that there is belief amongst 
both employers and employees that implementation of work-life balance initiatives would have a positive and noticeable impact on the workplace The benefits of worklife balance practices were readily identified by employers and included, the retention of quality staff, being able to attract quality staff, higher productivity, motivation and happier workplaces (UMR Insight, 2003). The researchers noted a degree of alignment between employers and employees on this issue; both groups tended to believe work life balance was positive.

\section{Conclusion}

The Work-Life Balance Project has identified that there are a range of contributors to work-life balance outcomes that will deliver benefits in different ways. The WorkLife Balance Project has not focused on telling people how to live their lives, but rather, recognised that each person needs to find their own desired balance. This requires "give and take" with constructive discussion, compromise and negotiation.

The Government also has a role to play in developing work-life balance solutions, while recognising that there is no such thing as a "quick fix" solution. It has a role as a significant employer, in developing policy and in facilitating relevant information being available to workers and workplaces, especially small and medium sized enterprises. The Government is currently considering the issues that were raised during the consultation and will respond early in 2005 .

New Zealanders work hard and value quality of life and generally consider that they have good work-life balance. Nevertheless, consultation undertaken as part of the Work-Life Balance Project has found common themes and concerns emerging where concerns lie among employers and employees. Tailoring solutions to meet the needs of employers, employees and their families will require collaboration that takes into account balance the needs of workplaces with the needs of individuals. There is a shared desire for New Zealand to be a great place to live and work. It is in everyone's interests; whether it is individuals seeking flexible solutions, employers trying to fill skill shortages in an intensely competitive international market for talent, or the government in seeking improved economic growth, to find innovative solutions that work in New Zealand.

\section{References}

American Business Collaboration (October 2004) Generation and Gender in the Workplace.

Callister, P. (Nov 2004) "The future of work within households: Understanding household-level changes in the distribution of hours of paid work".

Department of Labour (July 2004) Achieving Balanced Lives and Employment: What New Zealanders are saying about Work-Life Balance.

Gravitas Research and Strategy (August 2003) Evaluation of the Implementation of Paid Parental Leave

Growth and Innovation Advisory Board. (2004). "Investigating New Zealanders Attitudes to Growth and Innovation".

International Labour Organisation (2004) Working Time and Workers' Preferences in Industrialized Countries: Finding the Balance.

Ministry of Social Development (2004) Social Report 2004.

NZCTU (2002). "Thirty Families: The Impact of Long Working Hours on Families"

Skilling, D. (September 2004) "Getting Growth" Unlimited Magazine p. 8.

State Services Commission (April 2002) Career Progression and Development Survey 2000.

UMR Insight (October 2003) Perceptions and Attitudes to Work-Life Balance in New Zealand: A Qualitative Study 